\title{
Contactless safety evaluation of damaged structures through energetic criteria
}

\author{
Luis Saucedo-Mora (10 I Ma Carmen Andrade Perdrix I Cecilio López Hombrados I \\ Javier Barroso Sanchez I Ana Zamora Bragado
}

Institute Eduardo Torroja for Construction

Sciences, Consejo Superior de

Investigaciones Científicas, 28033 Madrid, Spain

\section{Correspondence}

Luis Saucedo-Mora, Institute Eduardo Torroja for Construction Sciences, Consejo Superior de Investigaciones Científicas, 28033 Madrid, Spain.

Email: luis.saucedomora@ietcc.csic.es

\section{Funding information}

Secretariat of State for Research, Development and Innovation of the Spanish government, Grant/Award Number: IJCI-201419362; Secretariat of State for Research, Development and Innovation, Grant/Award Number: IJCI-2014-19362

\begin{abstract}
Summary
The reinforced concrete structures need to be monitored to ensure their structural integrity, but sometimes those measurements are very local, and the instrument is complex to locate physically in the structure and may interfere on it. Digital Image Correlation is a noncontact and nondestructive experimental technique capable to measure the displacement field in a big region of a structure with a great accuracy. This allows extracting valuable information from the fracture processes of reinforced concrete structures, critical for the evaluation of the structural integrity. The measurement of the energy dissipated by the structure is essential for the identification of the strength mechanisms that are failing in the structure and to identify a proper repair. Also, using fracture mechanics, other valuable information are extracted from the fracture processes of the reinforced concrete beam, such as the Modes I and II fracture energy released at each loading step, which is essential to evaluate the elastic energy that the structure can accumulate before collapse. The examples enable to anticipate the importance of Digital Image Correlation for future large scale studies of fracture in concrete and other materials related to construction.
\end{abstract}

\section{KEYWORDS}

Digital Image Correlation, energy release rate, fracture mechanics, integrity, stress intensity factor

\section{1 | INTRODUCTION}

For any solicitation, the structure always behaves following the energetic balance where the external work is mainly transformed into kinetic, elastic, plastic, and fracture energies. ${ }^{[1]}$ This is altered in a damaged structure, which has a lack of capacity to store elastic energy, releasing part of the external work as fracture energy, and allowing the cracks to grow influenced by the local material and geometry. ${ }^{[2]}$ Through the identification of the cracks tips and measuring the full field displacement, the stress intensity factors (SIFs) can be calculated as well as the energy release rate of each crack $^{[3]}$ in shear and tension. ${ }^{[4]}$ This information is valuable to determine the integrity of a structure. Showing that the strain state along the structure, and especially around each crack tip, can predict the microstructural mechanisms failing in the material. ${ }^{[5]}$ This can be used to identify the repairs required and to evaluate the safety of the structure through its total energy release rate, with independence of the loading history. Our results demonstrate how a contactless and affordable technique can tackle this highly demanded problem, with advantages with respect to other monitoring techniques. ${ }^{[6--8]}$ Digital Image Correlation (DIC) is a robust, nondestructive, and noncontact experimental technique widely used in the last decades for micromechanical characterization of materials. ${ }^{[6]}$ It uses images of a surface to measure its local displacements, being the input of DIC, a pair of images (i.e., the reference and deformed), which are divided in windows to correlate them and measure its displacements. ${ }^{[9]}$ This technique is well known, although is still very scarcely 
employed in real size concrete structures with successful results. The great complexity and size of the concrete elements were a drawback for the use of DIC, but the information that can be extracted with it is essential for the full characterization of the fracture processes of concrete, which has encouraged its application. Thus, among others, ${ }^{[10-13]}$ in 2006 , Küntz et al. ${ }^{[14]}$ applied DIC to measure the stability of a shear crack in a reinforced concrete bridge during loading. In 2012, Lee et al. ${ }^{[15]}$ compared the measurements done with DIC in a reinforced concrete structure with foil and vibrating wire strain gauges. They concluded that DIC is more versatile and as accurate as the others. In 2013, Dutton et al. ${ }^{[16]}$ used DIC to measure the curvature of a reinforced concrete beam of $3.8 \mathrm{~m}$ long. They did it imaging 2 regions of $600 \times 400 \mathrm{~mm}$ where the deflection was calculated. And in 2014, Fayyad and Lees ${ }^{[17]}$ used it to measure the opening of a crack in a notched beam of $0.8 \mathrm{~m}$ long.

This paper will focus on exploring the possibilities of application of DIC as a health monitoring technique for civil structures, mainly motivated by its noncontact and nondestructive nature.

The use of DIC to characterize the fracture of a reinforced concrete beam is also very useful to understand the complex fracture processes ${ }^{[18]}$ and the evolution of the crack behavior. Its combination with fracture mechanics allows us to extract more characteristics of the fracture processes such as the relationship between Modes I and II and the transition between both. For this, the SIFs are used and calculated from the strain field ahead of the crack tip. There are many solutions for this calculation such as the interaction integral technique ${ }^{[19]}$ or the method of Yoneyama el at., ${ }^{[20]}$ but in this paper, we are using the classical polar equations of the linear elastic fracture mechanics. ${ }^{[3]}$ In this paper, we are able to measure the discontinuity created by a crack and the crack opening along the height of the beam, and to characterize the Modes I and II fractures. All those aspects, with the Fracture Process Zone, ${ }^{[21]}$ are the keys to characterize the integrity of reinforced concrete structures.

The paper is structured in three parts: the description of the experimental tests, the methodology used in the post-process to calculate the stress intensity factors and the fracture energy, and the application of the proposed methodology to reinforced concrete beams. Figure 1 shows the flowchart of the methodology, showing a picture of the beam used for the analysis and the result.

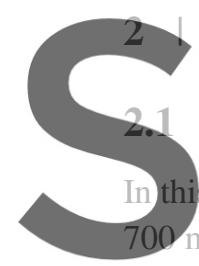
EXPERIMENTAL Fracture test of a
ase, the DIC method was
, and a $250 \times 200 \mathrm{~mm} \mathrm{~s}$
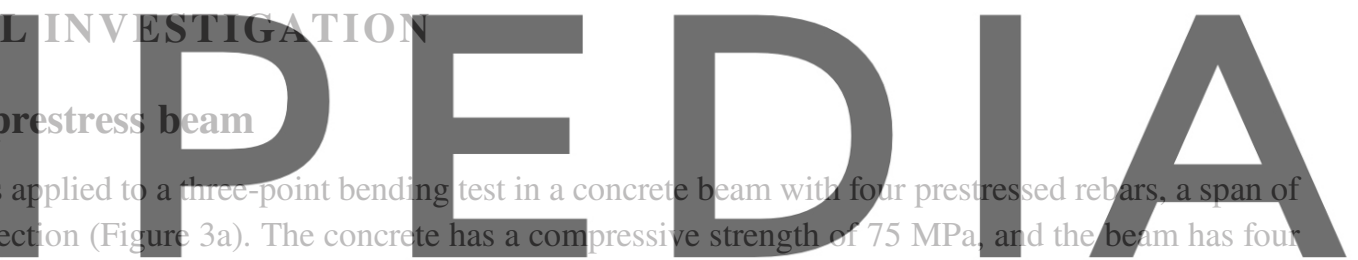

prestressed longitudinal rebars of a $1,670 \mathrm{C}$ steel with a diameter of $7.5 \mathrm{~mm}$ located two at $50 \mathrm{~mm}$ from the top of the beam, and

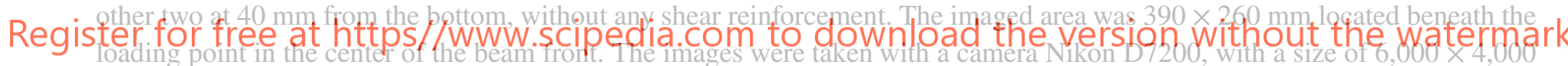
pixels (i.e., 24 Megapixels). Resulting in a pixel size of $0.065 \mathrm{~mm}$. The images are treated with the softwares Moire Analysis V0.956b ${ }^{[22]}$ and ImageJ $1.46 r,{ }^{[23]}$ using a windows size of $160 \times 160$ pixels and an overlap of the $50 \%$ with a single pass. This gives an error of $5 \mu \mathrm{m}$, measured with an undeformed image displaced with a rigid body movement. After the calculation with the deformed images, the displacement field was corrected for rigid body movements, rotation, and out of plane movements with the algorithm of Saucedo-Mora. ${ }^{[24]}$

\section{2 | Fracture test of two reinforced concrete beams}

A similar treatment was done for two reinforced concrete beams, with the same size of $4,000 \times 300 \times 250 \mathrm{~mm}(\mathrm{~S} / \mathrm{H} / \mathrm{W})$ but different reinforcement ratio and loading conditions. The compressive strength of the concrete used was $35 \mathrm{MPa}$ and the yield
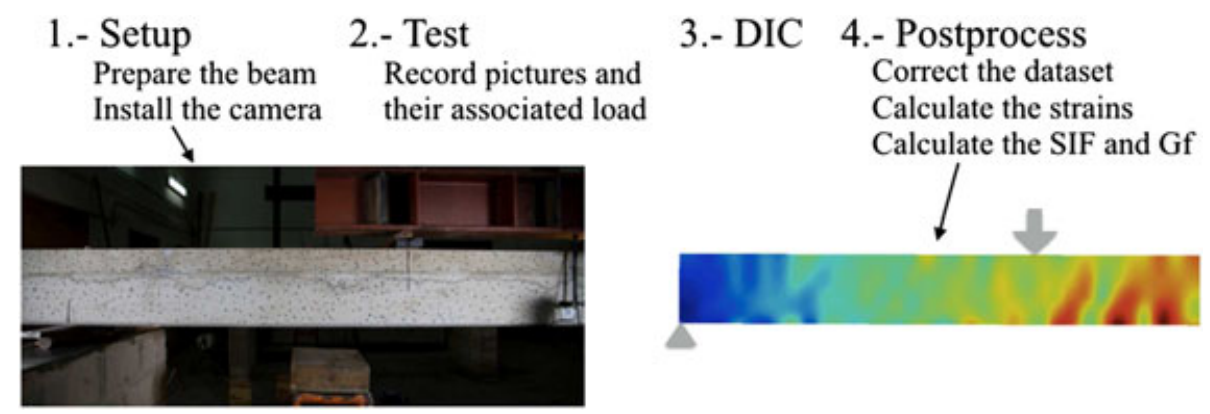

FIGURE 1 Flowchart of the full methodology, showing a picture of the beam used for the DIC and the strain field obtained in the post-process 
stress of the steel B500-S MPa. The first one was designed to reproduce a brittle failure given by shear, with a reinforcement of five rebars of $16 \mathrm{~mm}$ diameter, located at $25 \mathrm{~mm}$ from the bottom, and shear stirrups every $200 \mathrm{~mm}$ with a diameter of $6 \mathrm{~mm}$ (Figure 2a). This beam was tested with two loads located at $750 \mathrm{~mm}$ from the supports at each side. The second beam was designed to fail in a ductile way by an excess of bending moment. It is reinforced with two rebars of $12 \mathrm{~mm}$ diameter located at $25 \mathrm{~mm}$ from the bottom of the beam, and the two loads were located at $1330 \mathrm{~mm}$ from each support (Figure 2b).

The experimental process and setup were the same explained before, but for those beams, a window of $100 \times 100$ pixels with an overlap of $75 \%$ was used with a single pass, with an error of $0.022 \mathrm{~mm}$. The camera was located at $1,625 \mathrm{~mm}$ from the beam, imaging half of the beam, that is, $2 \mathrm{~m}$.

\section{3 | METHODOLOGY}

DIC is an experimental technique that measures the local movements of a deformed image when compared with a reference. To do that, the reference image is divided in overlapped regions called windows. Then a search algorithm finds each window in the deformed image based on the relative position of the pixels with different gray levels. As well, some algorithms incorporate deformation and rotation to this search, ${ }^{[25]}$ giving a higher accuracy than the ones that only consider the rigid body movements of the window. The first step is to convert the reference and deformed images in an 8-bit figure in gray scale, ensuring that both have the same number of pixels and size. Also it is essential to have a reference of a known length to measure the pixel size of the image (i.e., the length that corresponds to each pixel and allows us to measure the displacements of the image in mm). This is done with the software ImageJ $1.46 r .{ }^{[23]}$ Once preprocessed, we analyze the images with the software Moire Analysis V0.956 $\mathrm{b}^{[22]}$ where the $x$ and $y$ displacements of the image are extracted. Afterwards, the data is processed with a self-developed code in Python $3.3^{[24]}$ to correct the rigid body movements and rotation, the out of plane displacements, ${ }^{[26]}$ and to calculate the strain field using the linear elastic mechanics theory. Finally, the results are plotted in Paraview 5.0.0. [26]

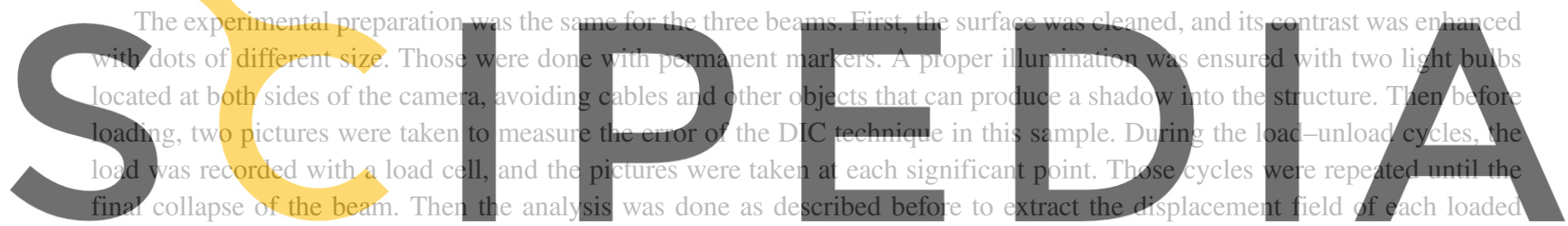

picture, using as a reference the unloaded from the previous step.

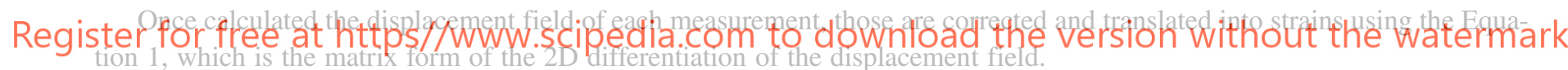

$$
\{\varepsilon\}^{i}=[B]^{T}\{u\}^{i},
$$

where $\varepsilon$ is the deformation tensor of the region $i, u$ its displacement calculated and corrected from DIC, and $[B]^{T}$ is the matrix containing the special derivatives of the shape functions. From the strain tensor, the eigenvalues and eigenvectors are calculated
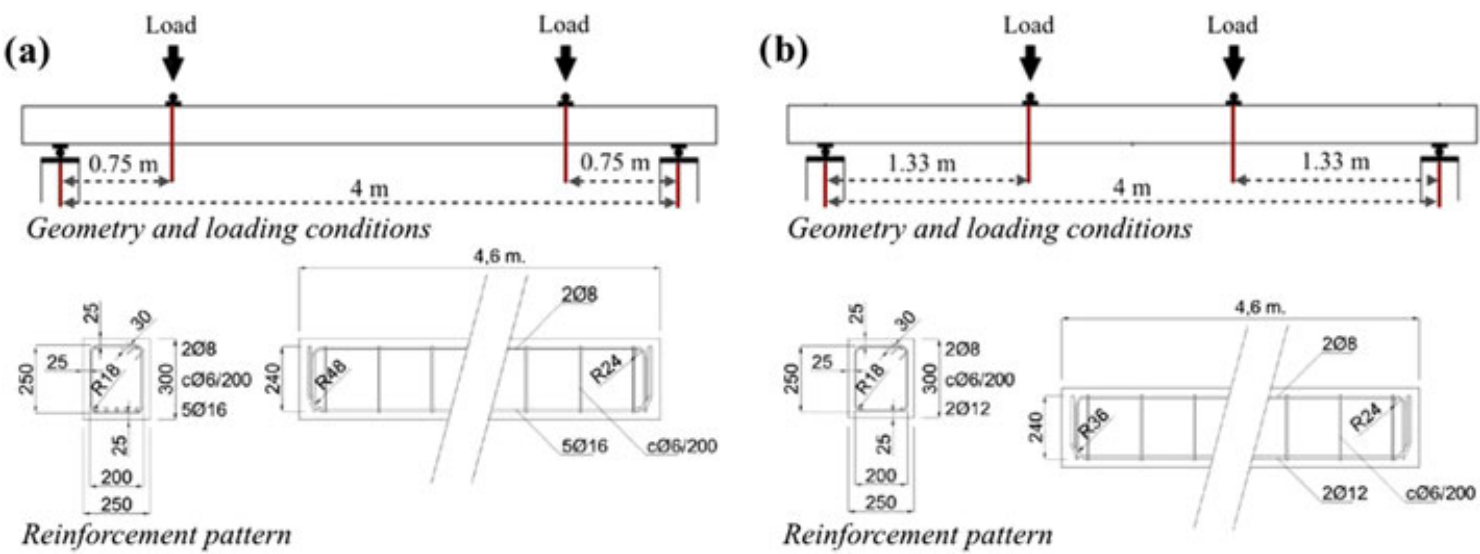

FIGURE 2 Geometry, loading conditions, and reinforcement pattern of the two reinforced concrete beams tested: (a) the beam of Figure 7 and (b) the beam of Figure 8 
to identify the maximum tensile strain and its orientation. From the strain tensor, the stresses can be calculated through the material properties through Equation 2:

$$
\{\sigma\}^{i}=\frac{E}{1-v^{2}}\left[\begin{array}{ccc}
1 & v & 0 \\
v & 1 & 0 \\
0 & 0 & 1-v
\end{array}\right]\{\varepsilon\}^{i} .
$$

Because we calculate the strain field in a big region of the beam, and we can identify the crack tip position, we have the strain field around the crack tip. It is given by a concentration of strains around it, which is characterized by the SIFs. ${ }^{[3]}$ Those are $\mathrm{K}_{\mathrm{I}}$ that represents the concentration caused by the Mode I grow of the crack and $\mathrm{K}_{\mathrm{II}}$ that is its equivalent for Mode II. From those two values and the local crack orientation, using linear elastic fracture mechanics, the full stress field around the crack tip can be reproduced with the polar equations (Equations 3-5). ${ }^{[3]}$ To calculate $\mathrm{K}_{\mathrm{I}}$ and $\mathrm{K}_{\mathrm{II}}$, the stress field given by Equations 3-5 is fitted to the experimental strains measured, which are translated into stresses through Equation 2 with the mechanical properties of the material, in this case a Young's modulus of $30 \mathrm{GPa}$ and a Poisson's ratio of 0.23 . Then $\mathrm{K}_{\mathrm{I}}$ and $\mathrm{K}_{\mathrm{II}}$ are calculated through the minimization of the difference between the analytical and measured stress fields, using the package Numpy ${ }^{[27]}$ of Python $3.3^{[28]}$ :

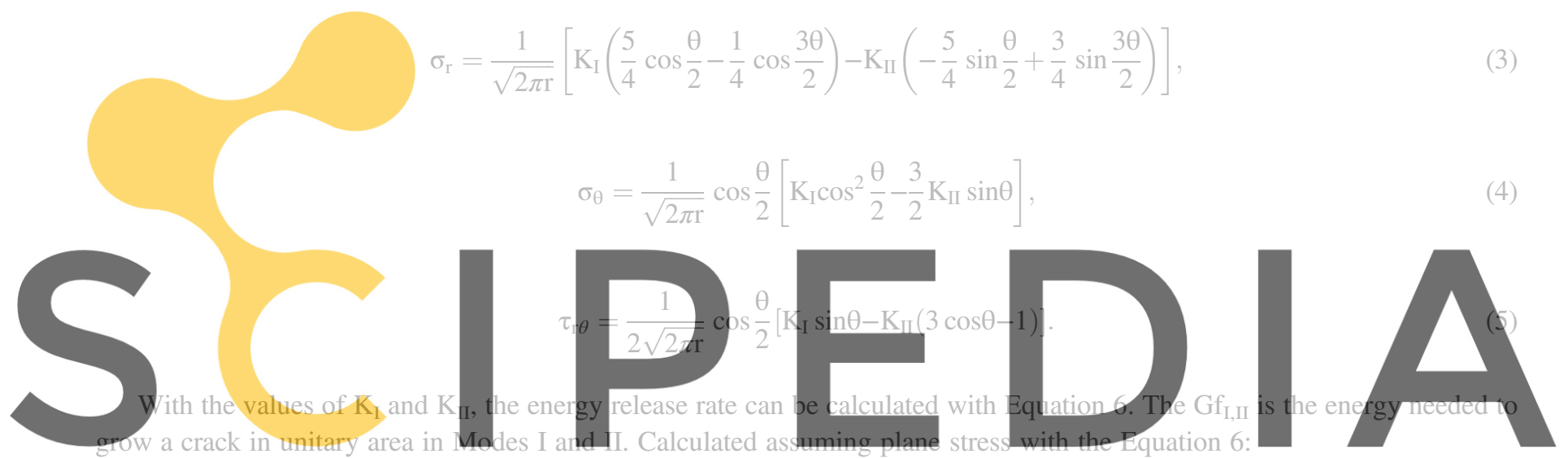

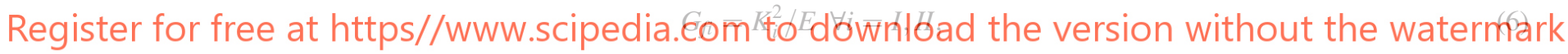

Where $\mathrm{E}$ is the Young's modulus of the material. Those local values of $\mathrm{G}_{\mathrm{f} \mathrm{I}}$ and $\mathrm{G}_{\mathrm{f} \mathrm{II}}$ show the regions releasing energy in one mode or the other, and the sum of those is an estimator of the integrity of the structure. Finally, the results are plotted with Excel and visualized with Paraview 5.0.0, ${ }^{[26]}$ translating the field data into VTU format.

This methodology, even if we do not know the loading history and the reinforcement pattern, can give key information about the structural integrity and the repair needed due to the independency of the measurements.

\section{4 | RESULTS}

Figure 3 is an example of a DIC measurement at an early stage of the cracking process (i.e., half of the peak load); it shows the relative strain between the loaded and the unloaded beam, without considering its initial strain given by the prestress. At the bottom, the crack initiation can be identified as a hot spot in Figure 3a. As expected, there are compressive strains in the top part of the beam. Figure $3 \mathrm{~b}$ shows the deflection of the beam, measured through DIC at the bottom of the image, and it is compared with the analytical deformation given by the beam theory. In this case, any big discontinuity in the deflection can be clearly identified, as in Figure $3 \mathrm{~b}$ for higher loads. It allows us to measure the opening of the central crack: $55 \mu \mathrm{m}$ at $260 \mathrm{kN}$ and $122 \mu \mathrm{m}$ at $280 \mathrm{kN}$. Also, when compared with the analytical solutions, the figure shows the nonlinearity of the beam once the first crack starts to grow. All the measurements shown in Figure 3 are done at loads, which are around half of the peak load.

\subsection{DIC to characterize the crack of a prestressed concrete beam}

The beam was tested with load/unload cycles with increasing peaks. For higher loads (Figure 4). the crack grows from the location spotted in Figure 3a at an earlier stage with the DIC analysis. The displacement field of the imaged region (i.e., the full field 
(a)

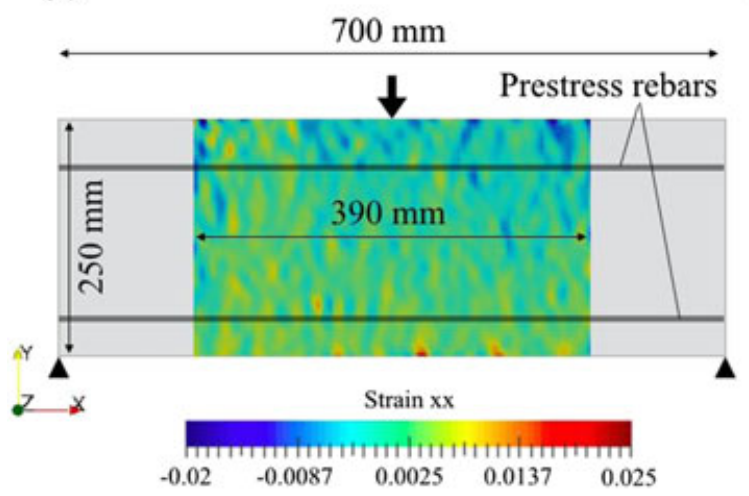

(b)

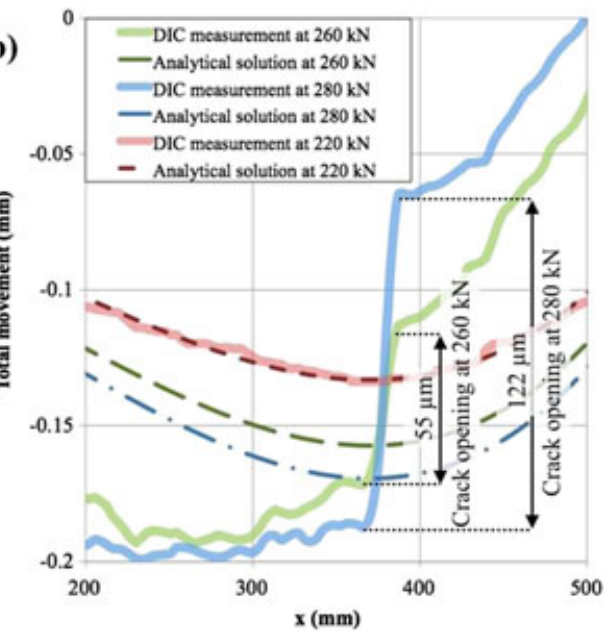

FICURE 3 Digital Image Correlation (DIC) of the beam at $220 \mathrm{kN}(45 \%$ of the neak load): (a) geometry of the beam and the tested beam surface (i.e., the full field measured) with the strain in $\mathrm{x}$ and (b) deflection of the beam measured with DIC compared with the analytical elastic solution
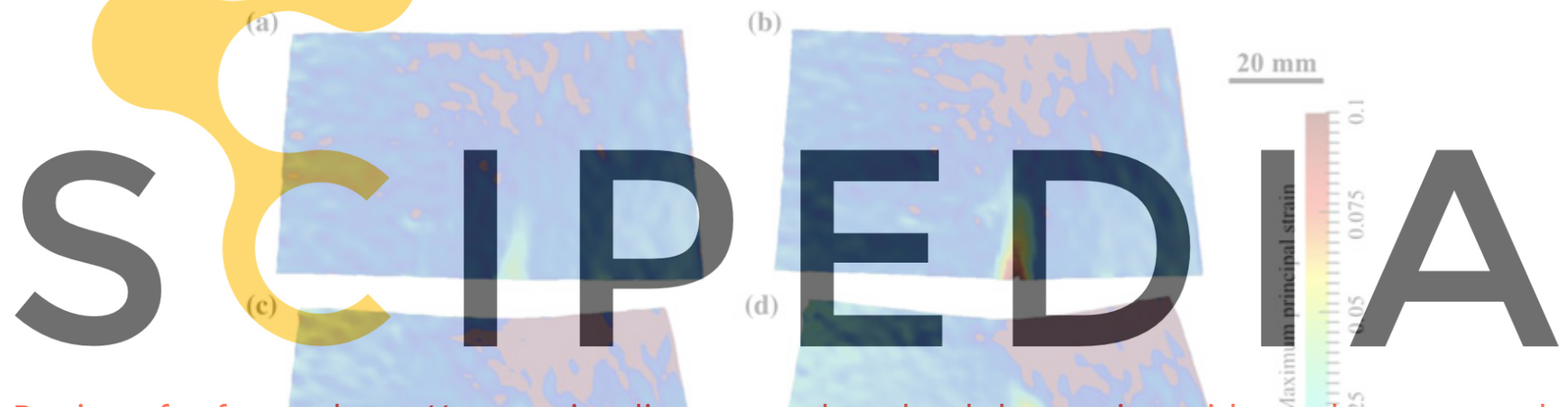

Register for free at https//www.scipedia.com th
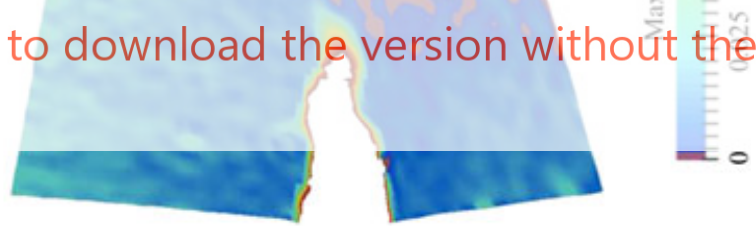

FIGURE 4 Deformed shape magnified 100 times and the superimposed strain field of the beam loaded at (a) $260 \mathrm{kN}$, (b) $280 \mathrm{kN}$, (c) $320 \mathrm{kN}$, and (d) $360 \mathrm{kN}$

measured) of the beam is extracted with DIC and magnified 100 times to plot the deformed shape of the beam with the strain field superimposed, as in Figure 4. This amplification shows that the displacements measured are not noisy, producing a homogeneous deformation. Also, applying an arbitrary threshold of 0.1 in the strain, the crack can be identified. Figure 4 shows the strain concentration around the crack tip and the Fracture Process Zone, as well as the regions under compression on the top of the beam.

Figure 4 shows the interaction between the Mode I crack originated beneath the loading point and the compressive region on the top of the beam. As the crack grows from 280 to $320 \mathrm{kN}$, the compressed region is displaced from the center of the beam, growing the crack around this region at $360 \mathrm{kN}$. In Figure 4, the regions in purple are confined under compression, and their displacement to one side of the loading point creates nonsymmetry in the curvature of the beam. Also, the displacement of the compressive regions leads to an increment of the shear in the right side of the beam that ends with a shear crack, which will be later introduced.

At $420 \mathrm{kN}, 70 \mathrm{kN}$ before the final load, another crack appeared on the right of the Mode I crack previously described. This crack goes from the region with high shear strain at the bottom of the beam to the region on the top confined under compression (Figure 4d). This crack grows dynamically, appearing with its $85 \mathrm{~mm}$ length between 400 and $420 \mathrm{kN}$. As a comparison, the Mode I crack of the center grows $20.1 \mathrm{~mm}$ in this gap of $20 \mathrm{kN}$. Those compressions are relative to the reference measurement 
at the start of the test, so the compression given by the prestress is not measured here. Figure 5 shows the $x$ and $y$ displacement field, and the $x x$ and $x y$ strains superimposed with the real cracks of the beam. The agreement between the DIC measurements of regions with high strains and the fracture paths are remarkable and shows the capability of this technique to be used for crack detection.

Figure 5a is the $x$ displacement field. As expected, the cracks introduce a discontinuity in the deformation, being bigger the jump of the central crack. Figure $5 \mathrm{~b}$ shows the $y$ displacement field where the biggest discontinuity is caused by the crack on the right. It needs to be mentioned that all the spurious movements were corrected from the raw DIC measurements, ${ }^{[2]}$ which is why all the movements are relative to the center of the image. Also, there is a region with a poor correlation, without data due to a common error of the technique at the crack border.

Figure $5 \mathrm{c}, \mathrm{d}$ is the $x$ strain and the shear strain. Those show clearly that the central fracture is a Mode I crack that was created and is growing in pure tension. As well the shear on the central crack is very low. The crack on the right produces a high concentration of shear strain along its path (Figure 5d), but in the crack tip its growth is governed by Mode I (Figure 6). Also, the tensile strain is very low when compared with the central one in Figure 5c. It shows that as an average at this load, the central is a Mode I crack and the one on the right is a Mixed-Mode crack. But this can lead towards a wrong interpretation of the failure of the beam, because all the energy that the two cracks have released was in Mode I, except the local releasement of the Crack 1 in Mode II when it crossed the prestressed reinforcement. This is different in the reinforced concrete beams, where the growth of the side cracks with curved trajectories are governed by shear. In this case, we can state that the prestress enhances the

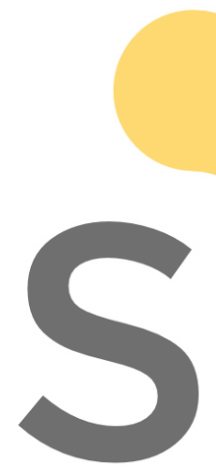

Register for free at https//www.scipedia.com to
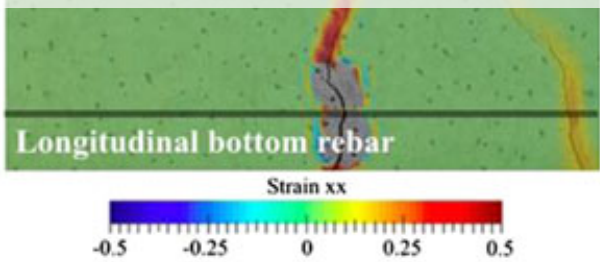

(e)

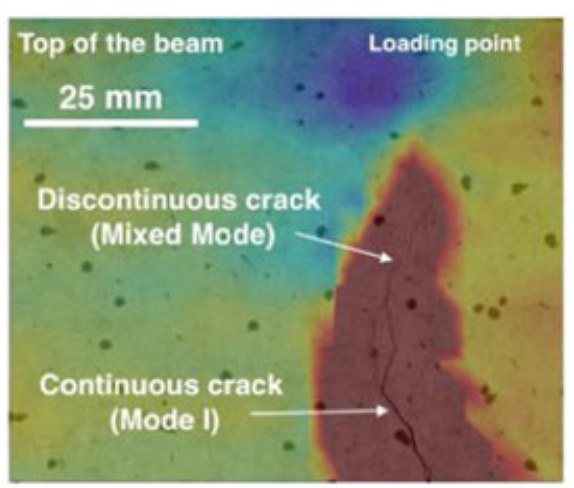

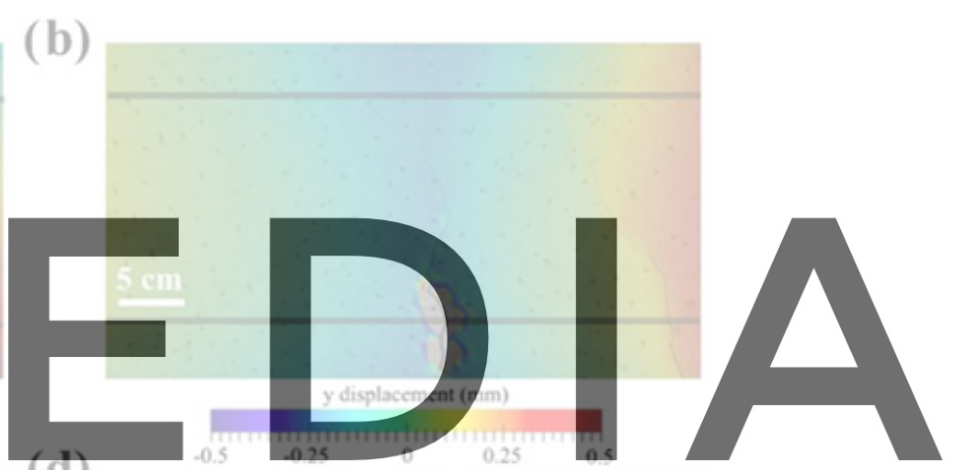

(d)

nload the version without the watermark
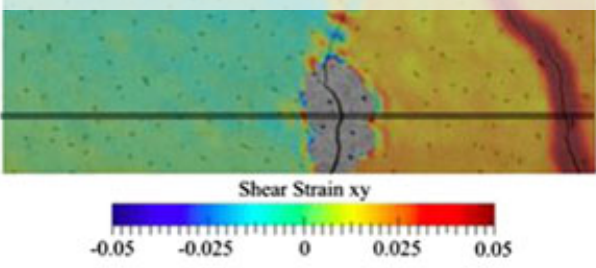

(f)
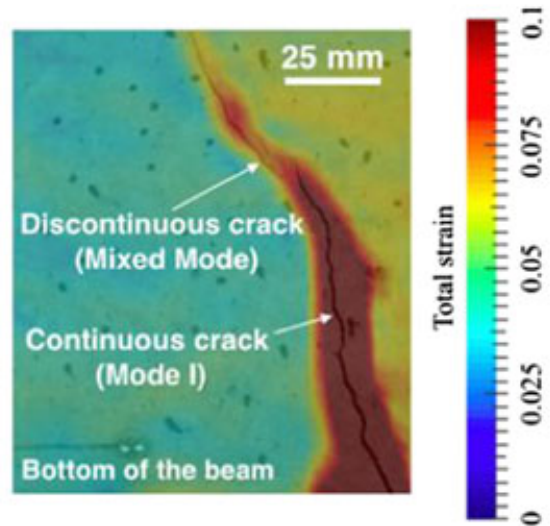

FIGURE 5 Digital Image Correlation study of the beam loaded at $420 \mathrm{kN}$ superimposed with the fractured beam, and two locations of the prestress rebars: (a) the $x$ displacement, (b) the $y$ displacement, (c) the strain in $x$, and (d) the shear $x y$ strain 


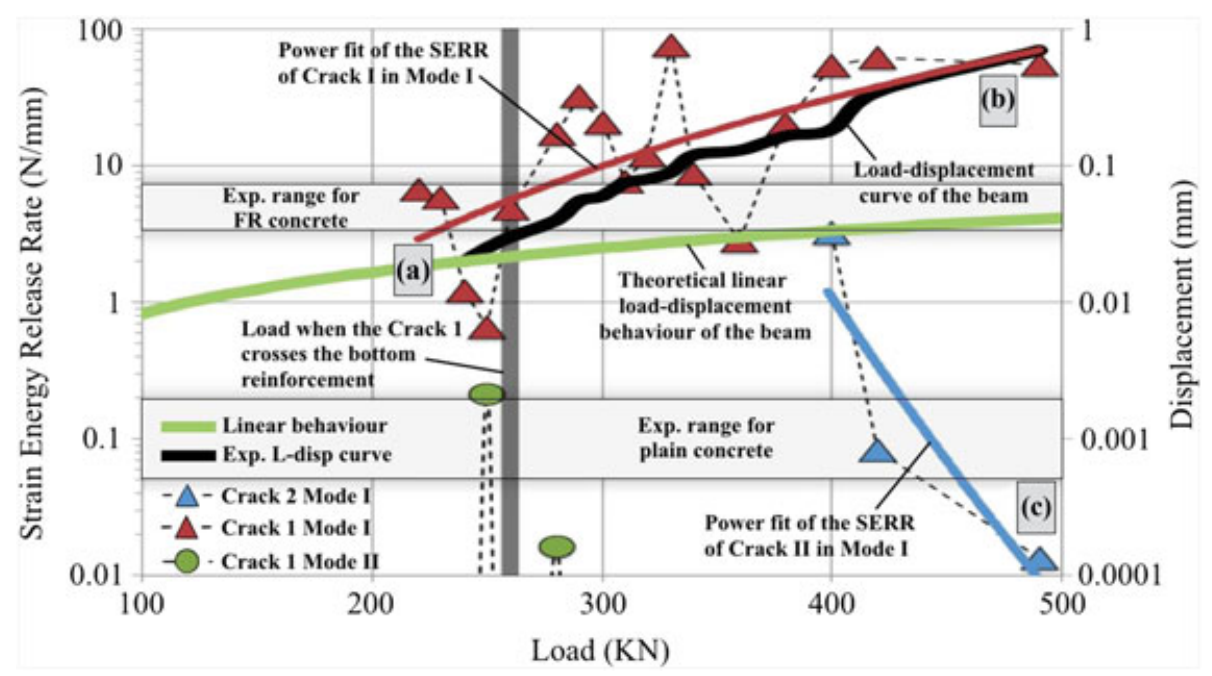

FIGURE 6 Relationship between the load-displacement behavior of the beam and the energy release rate of the two cracks at each point, in Modes I and II

mechanisms of the material to resist the Mode II failure, releasing the energy in Mode I. This is mainly the interlock of the aggregates that is higher in the crack tip because the prestress in the concrete increases the friction between the faces of the Fracture Process Zone. And with this, the mechanisms are enough to resist and prevent the Mode II releasement of energy. Figures 7 and 8 show the cases of reinforced concrete without prestress that cannot stop the releasement of energy in Mode II.
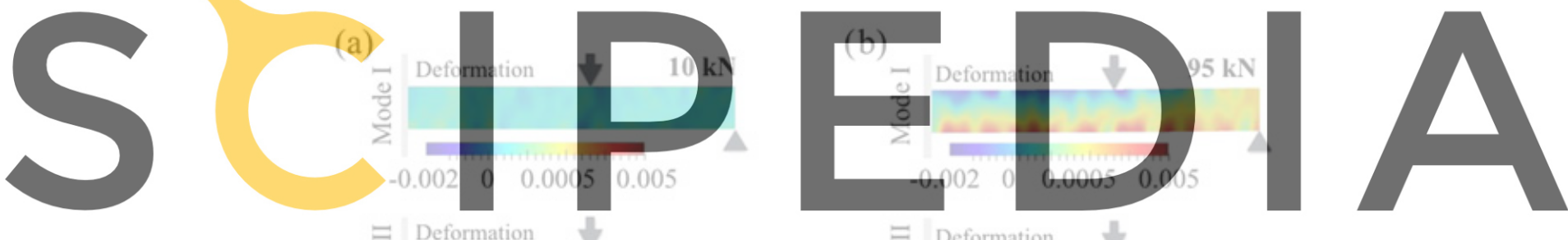

\section{$=$ Deformation}

Register for free at http̆s//www.scipedia.com
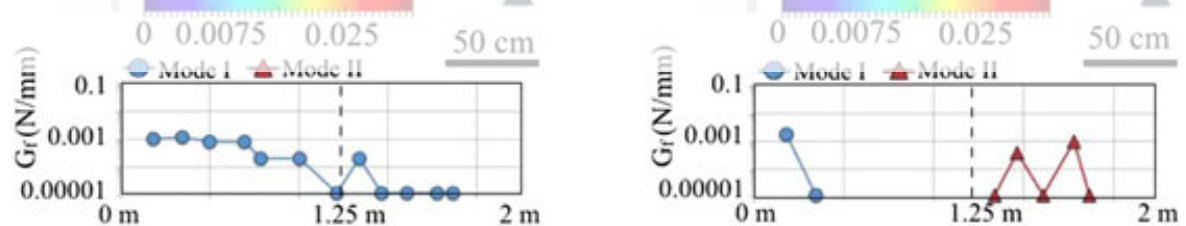

(c)
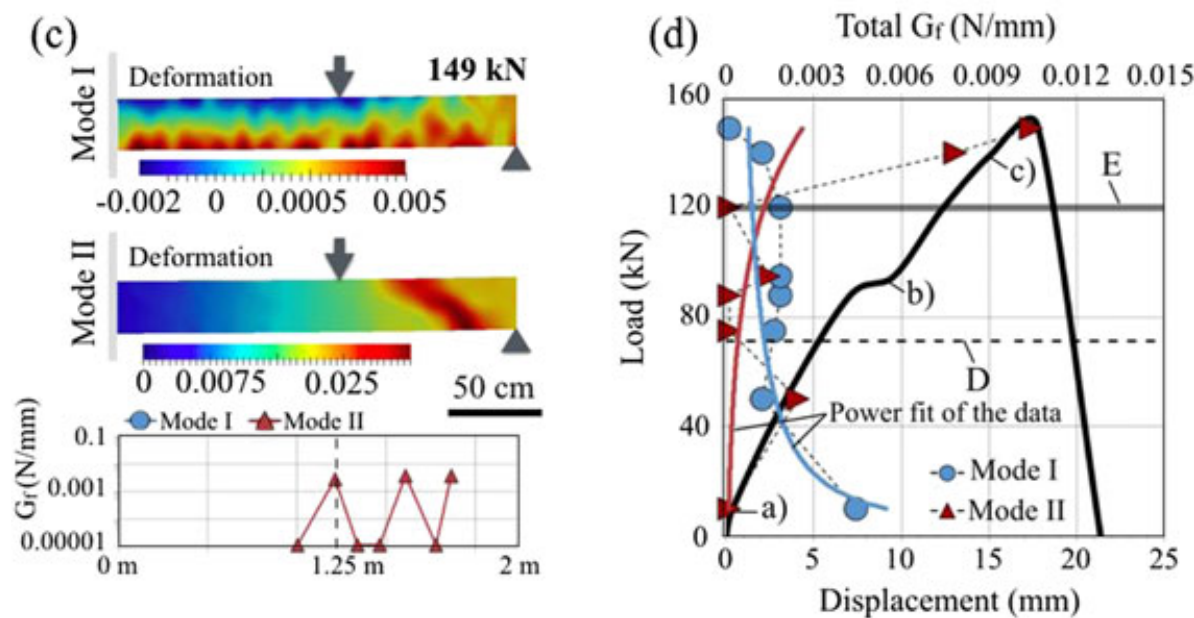

FIGURE 7 Strain field in Modes I and II for the beam and the energy release rate at $10 \mathrm{kN}$ (a), $95 \mathrm{kN}$ (b), and $149 \mathrm{kN}$ (c). In (d) the loaddisplacement behavior of the beam with the total strain energy release rate at each step in the secondary horizontal axis 
(a)
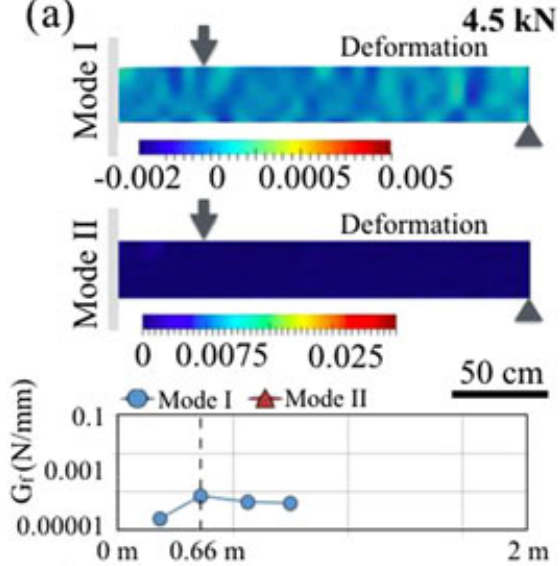

(c)

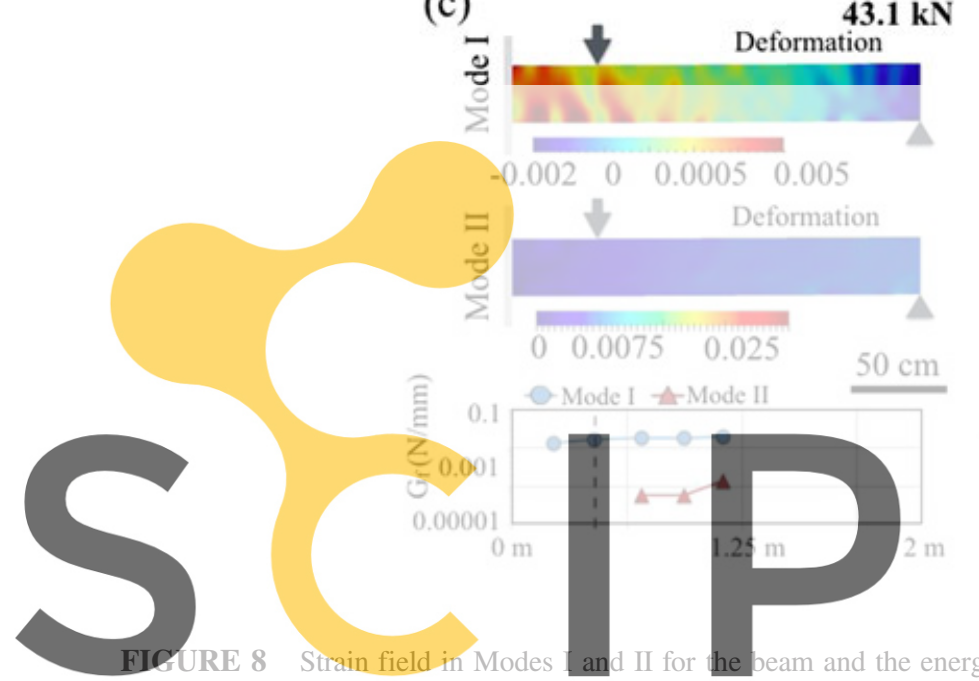

(b)
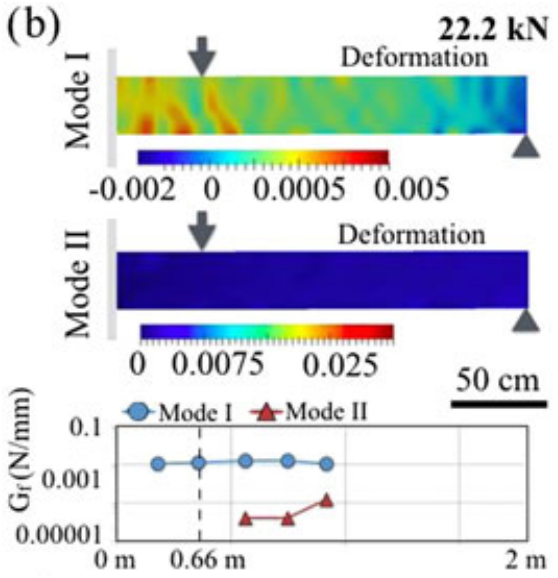

(d)

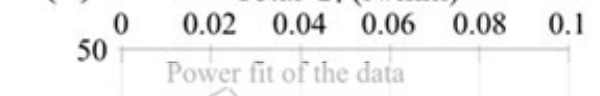

displacement behavior of the beam with the total strain energy release rate at each step in the secondary horizontal axis
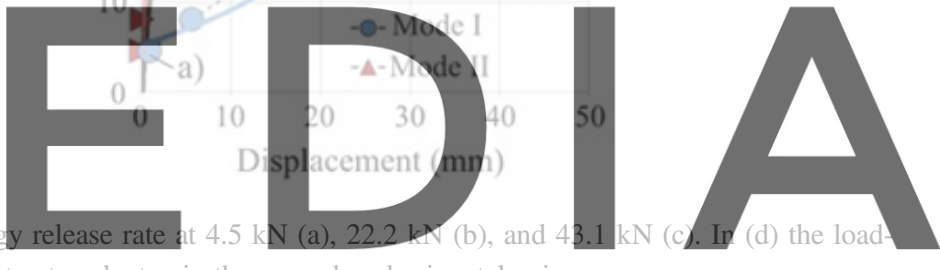

\section{Register for free at https//www.scipedia.com to download the version without the watermark}

\section{2 | Modes II and III interactions in reinforced concrete beams}

Figure 5 shows two cracks, one located in the center beneath the loading point (a) and other at $1 / 4$ of the span from the left support (b) at $420 \mathrm{kN}$. This is a beam of $700 \times 250 \times 200 \mathrm{~mm}$ with two prestressed wires of $7.5 \mathrm{~mm}$ diameter located at $40 \mathrm{~mm}$ from the bottom. With the superimposed total strain measured with DIC, each crack has regions of discontinuous cracking and a continuous crack. Showing that in a complex material, such as reinforced concrete, the crack propagation mode can change locally due to the heterogeneities, with independence of the previous crack path and orientation or its global behavior. This indeed gives valuable information about the integrity of a structure and its materials.

The results of Figures 6, 7, and 8 are quantitative measurements of the energy release rate of the different beams. In the classical fracture mechanics theory of Griffith, ${ }^{[3]}$ it is stated that the crack growth is related to the stress applied through a constant, which is the fracture energy $\left(\mathrm{G}_{\mathrm{f}}\right)$ or strain energy release rate. It means that the cracks release the elastic energy that the structure cannot store, leading to collapse when the previous level of elastic energy is required. Our results show that the cracks and their strain energy release rate are good estimators of the structural integrity. And can be decomposed in Modes I and II to identify the strength mechanisms of the material that are releasing the energy and need to be repaired, in order to reach the desired capabilities. Also, these measurements are independent of the loading history of the structure, and only the stiffness of the material is required.

Figure 6 shows the strain energy release rate of the two cracks shown in Figure 5 along the loading test. These were measured in load/unload cycles, taking the reference pictures on the unloads and the deformed ones after the reload, ensuring the independency of the measurements. Crack 1 is located in the center of the beam (Figure 5e) and Crack 2 at one side (Figure 5f). The Crack 1 appeared at $215 \mathrm{kN}$ (A of Figure 6) and started releasing energy in Mode I until it crossed the prestressed bars, when the crack release punctually energy in Mode II combined with Mode I. This result does not follow the classical fracture mechanics theory and can be given by the interlock effect of the reinforcement when the crack crosses it. Further tests need to be 
done to explain in detail every change of this plot. The strain energy release rate of this crack continues growing until the failure in point $\mathrm{B}$. The energy released is directly influencing the softening part of the load-displacement curve, showing the real mechanisms of the material causing the lack of structural integrity; in that case, a tensile failure. At $400 \mathrm{kN}$, the Crack 2 starts to grow, but perhaps it is inclined, the energy is released in Mode I, decreasing its strain energy release rate, which means that the internal mechanism of the material were capable to resist it. Globally, looking at any point of the full test, the energy is mainly released in Mode I, so if we want to repair it, we should act in the Mode I mechanisms, such as the reinforcement at the bottom of the beam. Also, thanks to the DIC strain field, the damaged region can be identified, making the repairs local.

The results of Figures 7 and 5 are from the full field measurements in two beams with the same geometry, a $4 \mathrm{~m}$ span and a cross section of $300 \times 250 \mathrm{~mm}$, but different reinforcement patterns and loading points. Only half of the beam was measured in both cases, which is enough to characterize the different behavior of each beam. Each one has a different failure mode as a consequence of their different steel content and boundary conditions. Figure 7 shows a beam with two loads at $750 \mathrm{~mm}$ from each support. At the beginning (Figure 7a), the beam released energy mainly in Mode I through the several cracks that appeared early at the bottom. Also, the energy dissipated is nearly constant between the loading points, which agree with the constant bending moment of this region. A repair at this stage would be focused on the Mode I mechanisms of the material. At half of the peak load (Figure 7b), the energy is only released by one crack close to the center in Mode I, and by two cracks between the loading point and the support in Mode II. This agrees with the general theory of structural mechanics, which states that the bending moment is higher between the loading points, and the shear is enclosed by the load and the support at both sides. It means that even without knowing the loading conditions of the beam, our results prove that with this methodology those can be identified. If we want to repair a beam with this pattern of strain energy release rate, we need to enhance the Mode I strength in the center of the beam and the Mode II close to the support. Near the collapse of the beam, Figure 7c shows how all the strain energy is released by the cracks between the support and the loading point only in Mode II; also the Mode II deformation shows clearly a typical curved shear crack. ${ }^{[29]}$ These cracks are growing in pure shear, differently than the ones of Figure 8, which are mixed mode cracks. This result is interesting because the general tendency is to classify the cracks according to their position within
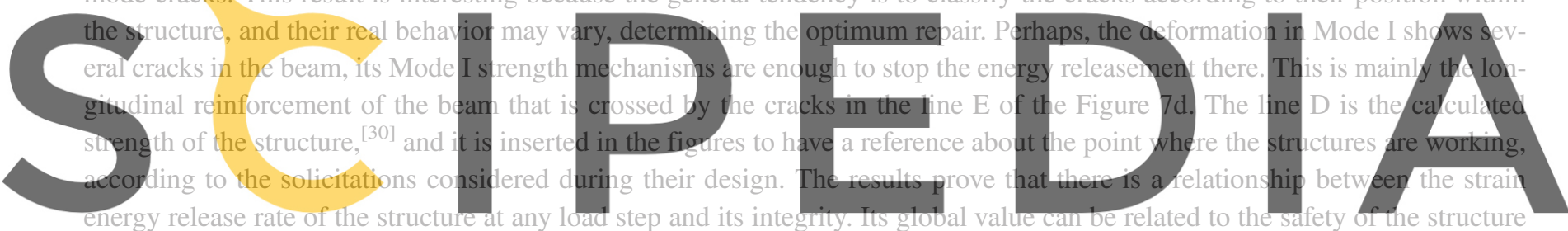

at every point, and locally, it can identify the regions to be repaired and how the material should be enhanced. But further exper-

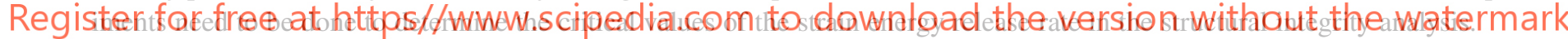

The beam of Figure 8 has the same dimensions as the previous but with a lower reinforcement ratio, and the loading points are closer to the center. In this case, the beam starts to release energy in Mode I in the region between loads as expected. And after passing the reinforcement (line E), and close to its calculated strength ${ }^{[30]}$ (line D), the Mode I energy release rate grows in all the region appearing some cracks releasing energy in Mode II as well as Figure 8b shows. It means that some cracks created in Mode I now release the energy both in Modes I and II, which is an observation of the well-documented mixed mode fracture. ${ }^{[2]}$ In Figure 8c, the strain energy release rate of the cracks continues growing in Mode I, which means that the microstructural mechanisms of the reinforced concrete are not capable to stop them, and the repair should be focused on their improvement in the central region. As Figure 8d shows, after point c, the reinforcement is completely plastified because it is not enough to resist the energy released in Mode I that leads to failure.

\section{5 | DISCUSSION}

The results presented here add versatility and reduce the cost of the inspections done with other methodologies, such as the ultrasonic pulse velocity ${ }^{[6,31]}$ and the high energy radiography. ${ }^{[7,8]}$ Due to the cost and complexity of those techniques, the most common procedure nowadays is the visual inspection, which cannot give accurate predictions of the structural integrity. Our results prove also that the visual inspection based on the orientation and number of cracks can lead to a misleading interpretation. In the experimental campaign, we tested a prestress concrete beam and two reinforced concrete beams, all under different loading conditions, with the target to produce different failure modes, releasing the energy in Modes I and II indistinctly. The materials have different strength mechanisms, ${ }^{[5]}$ and in the case of concrete, the Mode I (tension) is mainly resisted by the tensile strength of the cement matrix and the reinforcement, and the mechanisms of Mode II (shear) are the interlock of the aggregates and the inclined reinforcement. So the crack growth changes from one to the other depending on the weakest strength 
mechanisms at the crack tip and the solicitation. Previous experiments of biaxial and triaxial extension ${ }^{[32]}$ show how the inclination of the crack is closely related with the failure mode, which agrees with Griffith theory ${ }^{[33]}$ and the extensions of Irwin ${ }^{[34]}$ and Shah, ${ }^{[3]}$ but our data shows that perhaps the angle have a global influence, the crack can locally switch the failure mode without changing the angle, just because the weakest mechanisms of the material is locally different. It is capable to release energy in Modes I and II at the same time, showing that different material mechanisms are involved simultaneously and produce different effects. This is extremely important in the identification of the mechanisms to be repaired and the evolution of the structural integrity, because the main target is to allow the structure to store more elastic energy.

The results open a new paradigm in the use of photogrammetry information to calculate the safety and repairs needed in a damaged structure. It also proves that the visual inspections can lead to wrong interpretations because they are mostly based on the amount of cracks and their trajectory. The contactless nature of this methodology, and the reduced cost of its experimental equipment, paves the way for the application of this technique in the structural integrity evaluation of key buildings and infrastructures, where the safety after an earthquake, an accident, or degradation needs to be ensured. Further investigation needs to be done to accurately relate the value of the strain energy release rate with the structural integrity. And to identify the most suitable repairs to stop the energy releasement in Modes I and II. Our results prove that some cracks can grow in Modes I and II simultaneously, or switching from one to the other depending on the material locally crossed. Also, the Crack 2 in the prestress beam grow in Mode I, perhaps its position and trajectory are related to the shear cracks of beams without a prestress. A structure can release energy in different modes at different loads, changing the failure mode that compromises its integrity and the location of the region critically damaged. Showing that a global approach is needed to extend the fracture mechanics theory towards real cases, where the safety of the structure needs to be ensured with a small amount of information and local variations.

6 | CONCLUSIONS

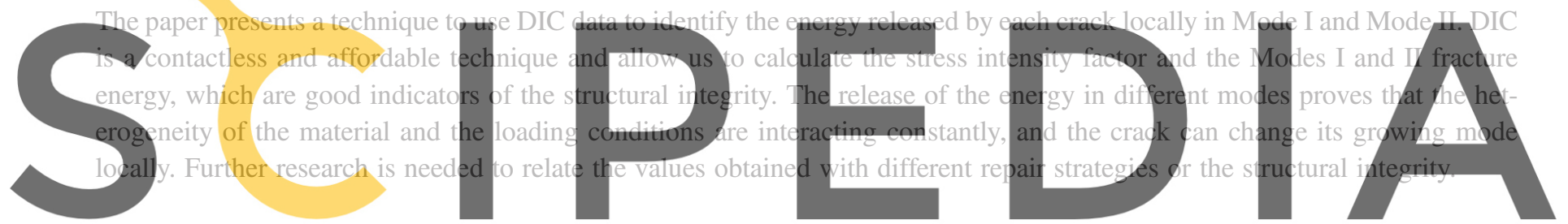

ACKNOWLEDGMENTS Register for free at https//www.scipedia.com to download the version without the watermark
Luis Saucedo-Mora wants to acknowledge the financial support given by the Secretariat of State for Research, Development and Innovation of the Spanish government under the grant IJCI-2014-19362 associated to a Juan de la Cierva Incorporation Fellowship. The authors want to acknowledge Jesús Rodríguez Santiago for the design and preparation of experiments of the reinforced concrete beams, which were done as part of the Master SEDUREC in the CSIC. The company Hijos De Gregorio Del Pliego S.L generously supplied the beams at no cost. The authors want to acknowledge as well Rogelio Sánchez Verdasdo for his support during the test with the manipulation and setup of the cameras.

\section{REFERENCES}

[1] Z. P. Bažant, L. Cedolin. Stability of structures: Elastic, inelastic, fracture and damage theories, 2010, World Scientific Publishing Co. Pte. Lfd., ISBN-13:978-981-4317-02-3.

[2] A. Carpinteri, N. Pugno, Nat. Mater. 2005, 4, 421.

[3] S. P. Shah, S. E. Swartz, C. Ouyang, Fracture mechanics of concrete: Applications of fracture mechanics to concrete, rock and other quasi-brittle materials, Wiley 1995. ISBN:978-0-471-30311-4. Retrieved from: http://eu.wiley.com/WileyCDA/WileyTitle/productCd-0471303119.html.

[4] J. M. Ramsey, F. M. Chester, Nature 2004, 428, 63.

[5] R. O. Ritchie, Nat. Mater. 2011, 10, 817.

[6] G. Karaiskos, A. Deraemaeker, D. G. Aggelis, D. Van Hemelrijck, Smart Mater. Struct. 2015, 24(11), 113001.

[7] P. Shaw, T. Pedersen, R. Serluppens, J. Nondestr. Test. 2000, 5.

[8] R. DeBraun Owen, NDT\&E Int. 1998, 31(6), 401.

[9] B. Pan, K. Qian, H. Xie, A. Asundi, Meas. Sci. Technol. 2009, 20, 062001, https://doi.org/10.1088/0957-0233/20/6/062001.

[10] M. Küntz, M. Jolin, J. Bastien, F. Perez, F. Hild, Can. J. Civ. Eng. 2006, 33, 1418, https://doi.org/10.1139/106-106. 
[11] Z. Dworakowski, P. Kohut, A. Gallina, K. Holak, T. Uhl, Struct. Control Health Monit. 2016, 23, 35, https://doi.org/10.1002/stc.1755.

[12] S. Rajaram, P. A. Vanniamparambil, F. Khan, M. Bolhassani, A. Koutras, I. Bartoli, F. Moon, A. Hamid, P. Benson Shing, J. Tyson, A. Kontsos, Struct. Control Health Monit. 2017, 24, e1903, https://doi.org/10.1002/stc.1903.

[13] A. Shariati, T. Schumacher, Struct. Control Health Monit. 2016, e1977, https://doi.org/10.1002/stc.1977.

[14] E. Speranzini, S. Agnetti, Struct. Control Health Monit. 2014, 21, 1015, https://doi.org/10.1002/stc.1629.

[15] C. Lee, W. A. Take, N. A. Hoult, M.ASCE, J. Comput. Civ. Eng. 2012, 26(6), 795, https://doi.org/10.1061/(ASCE)CP.1943-5487.0000182.

[16] M. Dutton, W. Take, N. Hoult, J. Bridg. Eng., 2014, 19(3). https://doi.org/10.1061/(ASCE)BE.1943-5592.0000538, 05013001.

[17] T. M. Fayyad, J. M. Lees, Procedia Materials Sci. 2014, 3, 1585, https://doi.org/10.1016/j.mspro.2014.06.256.

[18] Z. P. Bazant, J. Planas, Fracture and size effect in concrete and other quasibrittle materials, CRC Press 1997. ISBN:084938284X 9780849382840.

[19] J. Dolbow, M. Gosz, Int. J. Solids Struc. 2002, 39(9), 2557, https://doi.org/10.1016/S0020-7683(02)00114-2.

[20] S. Yoneyama, T. Ogawa, Y. Kobayashi, Eng. Fract. Mech. 2007, 1399.

[21] L. Saucedo-Mora, R. C. Yu, G. Ruiz, Int. J. Fract. 2012, 178, 97, https://doi.org/10.1007/s10704-012-9769-0.

[22] B. Pan, Z. Wang, Z. Lu, Opt. Express 2010, 18(2), 1011, https://doi.org/10.1364/OE.18.001011.

[23] W.S. Rasband. ImageJ, U. S. National Institutes of Health, Bethesda, Maryland, USA, http://imagej.nih.gov/ij/, 1997-2015.

[24] L. Saucedo-Mora. Correction of the spurious strains and displacements caused by out of plane movements in Digital Image Correlation (DIC) with a single camera. 2016. (submitted)

[25] H. A. Bruck, S. R. McNeill, M. A. Sutton, W. H. Peters III, Exp. Mech. 1989, 29(3), 261, https://doi.org/10.1007/BF02321405.

[26] J. Ahrens, B. Geveci, C. Law, ParaView: An end-user tool for large data visualization, Visualization Handbook, Elsevier, 2005, ISBN-13: 9780123875822. Retrieved from: https://www.paraview.org/publications/.

[27] S. van der Walt, S. C. Colbert, G. Varoquaux, Comp. Sci. Eng. 2011, 13, 22, https://doi.org/10.1109/MCSE.2011.37.

[28] G. van Rossum, Python tutorial, technical report CS-R9526, Centrum voor Wiskunde en Informatica (CWI), Amsterdam, May 1995. Retrieved from: https://mail.python.org/pipermail/python-list/2002-May/152619.html.

[29] M. Zakaria, T. Ueda, Z. Wu, L. Meng, J. Adv. Concr. Technol. 2009, 7(1), 79.

[30] EN 1992-1-1: Eurocode 2: Design of concrete structures-Part 1-1: General rules and rules for buildings. Authority: The European Union Per Regulation 305/2011, Directive 98/34/EC, Directive 2004/18/EC, 2004.

[31] R. Demirboga, I. Türkmen, M. B. Karakoç, Cem. Concr. Res. 2004, 34(12), 2329.

[32] X. M. Kong, N. Shlüter, W. Dahl, Eng. Fract. Mech. 1995, 52(2), 379.

[33] A. A. Griffith, Proc. Int. Congr. Appl. Mech 1924, 1, 55.

[34] G. R. Irwin, J. Appl. Mech (ASME) 1957, 24, 361 (Sec. 12.1).

How to cite this article: Saucedo-Mora L, Andrade Perdrix MC, López Hombrados C, Barroso Sanchez J, Bragado AZ. Contactless safety evaluation of damaged structures through energetic criteria. Struct Control Health Monit. 2018;25: e2060. https://doi.org/10.1002/stc.2060 